\title{
Pesticides drive risk of micropollutants in wastewater-impacted streams during low flow conditions
}

Nicole A. Munz ${ }^{\mathrm{a}, \mathrm{b}}$, Francis J. Burdona, Dick de Zwart ${ }^{\mathrm{d}}$, Marion Junghans ${ }^{c}$, Laura Meloa, Marta Reyes ${ }^{a}$, Urs Schönenberger ${ }^{a}$, Heinz P. Singera, Barbara Spychera, Juliane Hollender ${ }^{a, b, *}$, Christian Stamma

aEawag, Swiss Federal Institute of Aquatic Science and Technology, 8600 Dübendorf, Switzerland bInstitute of Biogeochemistry and Pollutant Dynamics, ETH Zürich, 8092 Zürich, Switzerland 'Swiss Centre for Applied Ecotoxicology Eawag-EPFL, 8600 Dübendorf, Switzerland dMermayde, Groet, The Netherlands

${ }^{*}$ Corresponding author. Present address:

Eawag, Swiss Federal Institute of Aquatic Science and Technology, 8600 Dübendorf, Switzerland. Tel: +41 5876554 93. E-mail: juliane.hollender@eawag.ch

This document is the accepted manuscript version of the following article:

Munz, N. A., Burdon, F. J., de Zwart, D., Junghans, M., Melo, L., Reyes, M., ... Stamm, C. (2017). Pesticides drive risk of micropollutants in wastewater-impacted streams during low flow conditions. Water Research, 110, 366-377. https://doi .org/10.1016/j.watres.2016.11.001

This manuscript version is made available under the CC-BY-NC-ND 4.0 license http://creativecommons.org/licenses/by-nc-nd/4.0/ 


\section{Abstract}

Micropollutants enter surface waters through various pathways, of which wastewater treatment plants (WWTPs) are a major source. The large diversity of micropollutants and their many modes of toxic action pose a challenge for assessing environmental risks. In this study, we investigated the potential impact of WWTPs on receiving ecosystems by describing concentration patterns of micropollutants, predicting acute risks for aquatic organisms and validating these results with macroinvertebrate biomonitoring data. Grab samples were taken upstream, downstream and at the effluent of 24 Swiss WWTPs during low flow conditions across independent catchments with different land uses. Using liquid chromatography high resolution tandem mass spectrometry, a comprehensive target screening of almost 400 organic substances, focusing mainly on pesticides and pharmaceuticals, was conducted at two time points, and complemented with the analysis of a priority mixture of 57 substances over eight time points. Acute toxic pressure was predicted using the risk assessment approach of the multisubstance potentially affected fraction, first applying concentration addition for substances with the same toxic mode of action and subsequently response addition for the calculation of the risk of the total mixture. This toxic pressure was compared to macroinvertebrate sensitivity to pesticides upstream and downstream of the WWTPs (SPEAR index). The concentrations were, as expected, especially for pharmaceuticals and other household chemicals higher downstream than upstream, with the detection frequency of plant protection products upstream correlating with the fraction of arable land in the catchments. While the concentration sums downstream were clearly dominated by pharmaceuticals or other household chemicals, the acute toxic pressure was mainly driven by pesticides, often caused by the episodic occurrence of these compounds even during low flow conditions. In general, five single substances explained much of the total risk, with diclofenac, diazinon and clothianidin as the main drivers. Despite the low predicted acute risk of $0 \%$ to $2.1 \%$ for affected species, a significant positive correlation with macroinvertebrate sensitivity to pesticides was observed. However, more effect data for pharmaceuticals and a better quantification of episodic pesticide pollution events are needed for a more comprehensive risk assessment.

Keywords: pesticides, pharmaceuticals, wastewater treatment plants, mixture toxicity, multisubstance potentially affected fraction (msPAF), risk assessment 


\section{Introduction}

Thousands of chemicals are in use daily for a wide range of purposes (Schwarzenbach et al., 2006) and hence enter the environment from various sources, such as agriculture, households and industry. This leads to the ubiquitous detections of such organic micropollutants in the $\mathrm{ng} / \mathrm{L}$ to $\mu \mathrm{g} / \mathrm{L}$ concentration range in surface waters (Loos et al., 2013; Schäfer et al., 2011). Conventional wastewater treatment plants (WWTPs), mainly designed for the removal of nutrients, only eliminate micropollutants to a limited extent, thus representing a major input source of micropollutants in the environment (Eggen et al., 2014). It has been shown that WWTP effluents contain a wide variety of substances, including not only pharmaceuticals, biocides and/or other typical household chemicals, but also many plant protection products (PPP) used in agriculture or for material protection in urban areas (Gerecke et al., 2002; Müller et al., 2002; Neumann et al., 2002; Wittmer et al., 2010). Furthermore, in most catchments in developed areas, urban and agricultural land use types co-occur (Couperus et al., 2016; Englert et al., 2015; Fairbairn et al., 2016; Gómez et al., 2012; Triebskorn et al., 2013; Wittmer et al., 2010). Therefore, for a holistic view of the risk it is important to include different substance types from various sources to link chemical exposure to observed effects in these aquatic ecosystems (Barber et al., 2013; Fairbairn et al., 2016; Triebskorn et al., 2013).

However, as it is often not possible to monitor hundreds of compounds regularly, focusing on priority mixtures whose compositions are representative for specific sources or sites is seen as a practical alternative (Altenburger et al., 2015). Moreover, regarding sampling strategies, further compromises may have to be made. Most studies have either collected temporally highly resolved samples at one or few sites (e.g. Wittmer et al., 2010) or included multiple sites but relied on single grab sampling given the logistical tradeoffs (Fairbairn et al., 2016; Gómez et al., 2012). Still, both sampling approaches are powerful tools for the understanding of pathway dynamics and apportioning sources and to help identify hotspots regarding risks towards the aquatic ecosystem.

The variety of organic micropollutants also poses challenges to properly quantify the ecotoxicological risk. Especially substances designed to be bioactive, such as pharmaceuticals or pesticides, are known to affect aquatic organisms and impact ecological systems at the trace-level concentrations detected in the environment (Malaj et al., 2014; Stalter et al., 2013). Different approaches for risk assessment have been used to estimate adverse effects on aquatic organisms. The European Water Framework Directive integrates environmental quality standards (EQSs) for priority substances as 
protective thresholds to detect whether the environmental concentration poses a risk to any species (EC, 2011). However, as EQSs are not established for many substances, one of the most common risk assessment approaches is the use of toxic units (TUs). TUs are calculated using the ratio between the environmental concentration of the substance and an effect concentration (e.g. $\left.\mathrm{EC}_{50}, \mathrm{NOEC}\right)$. In contrast to EQSs where assessment factors are used, TUs reflect the toxicity to single species and cannot be regarded as a protective threshold, because the possibility of more sensitive speciesis not taken into account.

Moreover, aquatic communities, comprised of many different species, are exposed to mixtures of a wide range of compounds, which generally induce toxic effects greater than the effects of the single substances alone (Backhaus \& Karlsson, 2014; Kortenkamp et al., 2009). A valuable tool that includes multiple species in the risk assessment is the species sensitivity distribution (SSD), which integrates the effect of a given substance on several species. Based on SSDs of single substances and their observed environmental concentrations, potentially affected fractions (PAF) can be calculated. Regarding mixture toxicity, the two following concepts have been established: concentration addition (CA; Loewe \& Muischnek, 1926) and response addition (RA; Bliss, 1939), which are mainly used for similarly and dissimilarly acting substances, respectively. It has been shown that the concept of CA is a reasonable worst-case estimation for single species tests (Junghans et al., 2006), but this assumption does not hold true for flat concentration-response curves. SSDs are often flatter than concentration-response curves, meaning this can be an issue when applying CA on SSD (Gregorio et al., 2013).

In real environmental mixtures both similarly and dissimilarly acting substances are present, thus justifying the combination of the two approaches. De Zwart and Posthuma (2005) introduced a twostep, mixed-model approach where mixture toxicity for substances of the same toxic mode of action (TMoA) is evaluated using the CA model, and the total mixture toxicity is then evaluated by combining the toxicities of the TMoA groups by the RA model. In combination with the concept of SSD, the "multisubstance potentially affected fraction" (msPAF), which describes the risk for whole species assemblages, can be predicted (De Zwart \& Posthuma, 2005). Changes in species abundances from field biomonitoring data repeatedly correlated with effects of mixtures predicted using the msPAF, highlighting the potential of this approach (Posthuma \& De Zwart, 2006, 2012). 
In this study, we investigated concentration patterns of a large number of micropollutants in 24 wastewater-impacted streams, as well as in the wastewater effluents, across independent catchments with different land uses. Our hypothesis was that the potential risk to aquatic organisms of these mixtures of micropollutants, using the risk assessment approach of the msPAF, correlates with biomonitoring data collected from the same sites. Specifically, we wanted to determine whether the risk for aquatic organisms in wastewater-impacted streams during low flow conditions is mainly driven by the higher concentrations of pharmaceuticals and other typical wastewater contaminants or if pesticides are a larger driver of risk. Furthermore, we aimed to assess how well priority mixtures describe environmental risks compared to extensive screening when tested across 24 sites.

\section{Methods}

\subsection{Sites and sampling strategy}

In total, 24 WWTPs distributed over the Swiss Plateau, the Jura mountains and the Prealps were selected, and were located in catchments with different land use patterns (Figure 1, Table S1.1). The sites were selected such that there was no WWTP upstream, a minimum of $20 \%$ wastewater downstream during low flow conditions, and no substantial changes in morphology or riparian vegetation between up- and downstream locations (Stamm et al., 2016). All WWTPs were operated as activated sludge treatments, except for Colombier which uses a trickling filter system. We defined an upstream and downstream location at each site, as described in detail in Burdon et al. (2016). Briefly, the downstream location was defined where the effluent was completely mixed across the channel; the upstream point was selected some $20 \mathrm{~m}$ upstream from the effluent discharge point. During the study period, the site Val-de-Ruz was found to have an additional underground input from a WWTP located upstream of the upstream site. This WWTP with $\sim 110$ connected inhabitants is comparatively small to the $\sim 11000$ connected inhabitants of the WWTP Val-de-Ruz. However, an influence on the chemical composition cannot be excluded and results from this site were interpreted with care.

Grab samples were taken over two consecutive years, including eight time points during low flow conditions. The field study was divided into two parts. In the first part, a sampling campaign was conducted in June 2013 at 12 sites and repeated in February 2014 at the same sites. Based on the results of the first campaigns, the temporal resolution was increased for the second part for the following 12 sites, where 6 bi-monthly campaigns were conducted from March 2014 to January 2015 (the exact sampling dates are reported in Table S1.2). For the analysis of organic micropollutants we 
collected water samples of $1 \mathrm{~L}$ upstream, downstream and at the effluent of the WWTPs (except for June 2013 , when no effluent was sampled). The samples were cooled and stored at $-20^{\circ} \mathrm{C}$ until analysis. For the second part, additional samples for heavy metals were collected, which were directly acidified and filtered on-site.

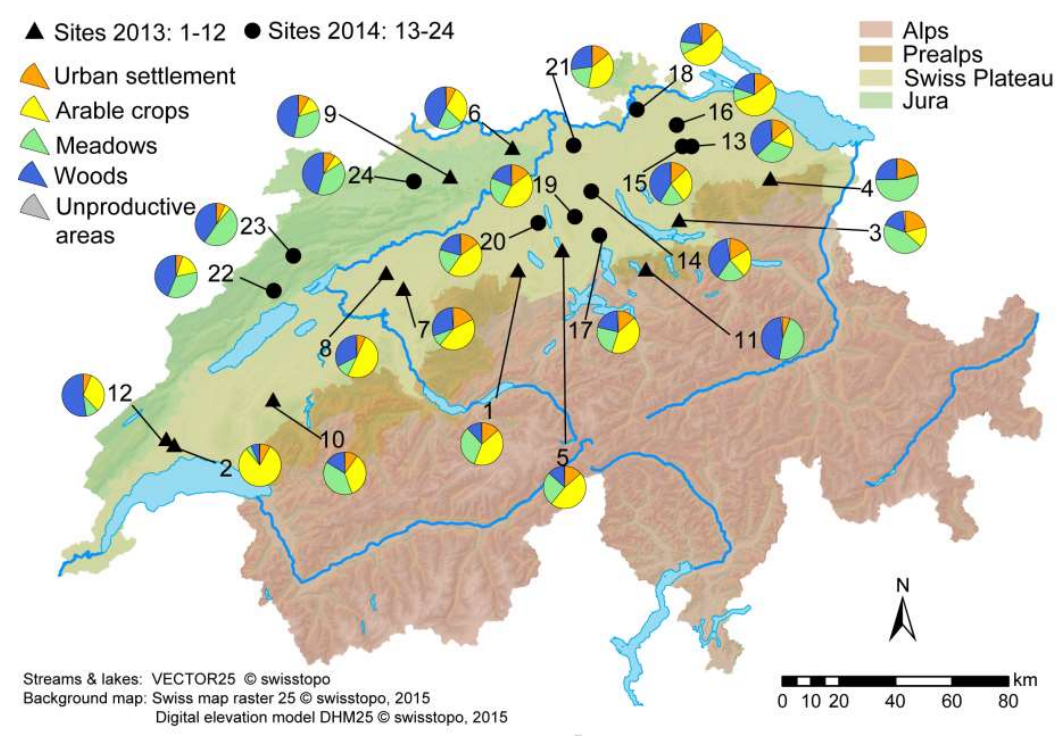

Figure 1: Location of the sampled wastewater treatment plants in Switzerland with the land use categories for each catchment shown in the pie charts (BFS, 2014). The aggregated land use categories and site names are listed in Table S1.1 of the supporting information.

\subsection{Substances analyzed}

For the upstream and downstream samples of June 2013 and May 2014 an extended screening of 389 organic micropollutants was conducted (Tables S1.2, S2.1). For all the other sites and time points a priority mixture of 57 substances was quantified. We prioritized the 57 substances to be relevant for Swiss streams using the following criteria: i) ubiquitous detections and effluent concentrations above $250 \mathrm{ng} / \mathrm{L}$ in municipal wastewater (Schymanski et al., 2014), ii) inclusion of different classes of pesticides (herbicides, fungicides, insecticides) with frequent detections (Moschet et al., 2014), iii) pesticides known to have high toxicity and/or a common mode of action (e.g. photosynthesis inhibitor herbicides), and iv) toxic pharmaceuticals with chronic EQS values below $1 \mu \mathrm{g} / \mathrm{L}$ (Ecotox Centre Eawag-EPFL, 2016). The compiled list of $\sim 100$ substances fulfilling at least one criteria was reduced by additional expert judgement (e.g. including different chemical structures) and analytical constraints (e.g. low recovery or high carryover during LC-MS analysis). The final priority mixture consisted of 28 pesticides (7 herbicides, 9 fungicides, 12 insecticides), 3 biocides, 22 pharmaceuticals/personal care 
products as well as 2 corrosion inhibitors, the sweetener sucralose, and caffeine as a tracer for releases of untreated wastewater. In this study, pesticides refer to PPP which are or were listed in the Swiss Ordinance on Plant Protection Products (OPPP, 2010) and to biocides, which are substances listed under the Ordinance on Biocidal Products (OBP, 2005). Substances approved as both PPP and biocide were categorized regarding their main usage in Switzerland (e.g. isoproturon as plant protection product and diuron as biocide) based on expert knowledge and former studies (e.g. Wittmer et al., 2010, Moschet et al., 2014). . Dissolved heavy metal concentrations were determined for Ag, $\mathrm{Cd}, \mathrm{Cr}, \mathrm{Co}, \mathrm{Cu}, \mathrm{Fe}$, , Mn, Ni, Pb and Zn during the March 2014 to January 2015 sampling period.

\subsection{Sample preparation and chemical analysis}

For the analysis of organic micropollutants, the samples of the June 2013 campaign were enriched with offline solid phase extraction (SPE) as described in Kern et al. (2009), whereas all the other samples were enriched with an automated online SPE similar to Huntscha et al. (2012). A liquid chromatography (LC) high resolution tandem mass spectrometry (HRMS/MS) setup was used for the analysis. The heavy metals were analyzed using high resolution inductively coupled plasma mass spectrometry (HR-ICP-MS). Further details are described in Section S2.1 of the supporting information (SI). Tables S2.1 and S2.2 list the LOQ of all organic substances analyzed.

\subsection{Data analysis}

To compare the variation of the concentrations of the different substances at the sampling locations upstream and effluent, a principal component analysis (PCA) was carried out with the R package "prcomp" (R Development Core Team, 2008). To assure equal contribution of each variable to the total variance the values were zero centered and scaled to have unit variance. Values below the LOQ were considered as zero. On the upstream data a 1/8-power transformation was performed because of the left-shifted distribution of the data set (many low concentration values). Only the 57 substances of the priority mixture were included.

For a land use analysis two different types of catchments were considered: i) the WWTP catchment for the correlation with effluent concentrations, and ii) the hydrological catchment for the correlation with upstream concentrations. The boundaries of the WWTP catchments correspond approximately to the boundaries of the communes discharging their wastewater into the respective WWTP (Herlyn \& 
Maurer, 2007). The hydrological catchments correspond to the catchments of the points of discharge of the WWTP effluents into the streams, as defined in the Swiss data set GAB-EZGG-CH (BAFU, 2013). For the two catchment types, we calculated the different areal fractions of the land uses using the Swiss land use statistics at the aggregation level of 27 different land use types (BFS, 2014). Areal fractions had to account for at least $2.5 \%$ in the given catchments to be considered in the further analysis. For comparison with our chemical data and to account for the high number of values below LOQ, correlations between the average detection frequency of single substance groups (e.g. pesticides) with the fraction of a specific land use type at the different sites (e.g. arable land) were performed. Only substances of the priority mixture were considered. For the land use analysis ArcGIS v10.3 was used.

\subsection{Risk assessment}

For the risk assessment we used the approach of the multi-substance potentially affected fraction (msPAF), which is described in detail in De Zwart and Posthuma (2005). Toxicity data for more than 1000 substances were gathered in a database (De Zwart, 2002). Only log-transformed acute EC50 values were used if possible, because repeatedly and empirically it was found that the msPAF based on acute median toxicity (EC50) comes the closest to the ecological effects that may be observed in the field (e.g. De Zwart et al., 2009; Posthuma \& De Zwart, 2006; Posthuma \& de Zwart, 2012). The detailed procedure on the treatment of the toxicity data is described in Section S3.1 of the SI. All substances were categorized based on their major TMoA, which was retrieved from literature and based on expert judgment. If the TMoA was not known, the substances were kept as single substances and not grouped with others. Finally, toxicity data for the calculation of the msPAF was available for 165 and 46 of the 389 and 57 analyzed substances in the extended screening and priority mixture data set, respectively. For isobaric substances analyzed as sums, only one of the two substances was considered. If toxicity data was available only for one, this value was taken for the substance pair. If toxicity data was available for both substances, the higher quality value was taken, or if of equal quality the more toxic value was taken. The definition of high quality data is described in Section S3.1 of the SI. Toxicity data used are listed in Table S3.1 in the SI. Values below LOQ were treated as zero if not stated differently. 
In a first step, the msPAF was calculated with the CA approach for all substances with the same TMoA using the cumulative density function of the normal distribution by Taylor-series approximation. This can be done using the Excel function $m s P A F_{C A}=N O R M . D I S T\left(\log \left(\sum c_{i} / E C 50_{i}\right)\right.$, mean $=0, \sigma_{i}$, cumulative $=T R U E)$, with $\mathrm{c}_{\mathrm{i}}$ as the environmental concentration of compound $\mathrm{i}$ of a specific TMoA group and $\sigma_{i}$ as the standard deviation of the SSD.

In a second step, the groups of TMOA were integrated based on the RA approach given by $\operatorname{msPAF}_{\mathrm{RA}}=1-\prod_{1}^{\mathrm{n}}\left(1-\mathrm{msPAF}_{\mathrm{CA}}\right)$ with 1 to $n$ groups of different TMoA. In the following mSPAFA $_{\mathrm{RA}}$ will be simply stated as msPAF.

To put our results into a regulatory context a comparison with risk quotients (RQs) based on acute MAC-EQSs (maximal allowable concentration) were calculated:

$R Q_{m i x}=\sum \frac{c_{i}}{E Q S_{i}}$

For this, published MAC-EQSs values from the centre for applied ecotoxicology in Switzerland (Ecotox Centre Eawag-EPFL, 2016) complemented with values from the EU Water Framework Directive (EU, 2013) were used, resulting in 60 and 36 MAC-EQSs for the screening and priority mixture data sets, respectively (Table S3.2).

\subsection{Macroinvertebrates}

Macroinvertebrates were collected in March/April 2013 (sites 1-12) and 2014 (sites 13-24) at the upstream and downstream locations following standard protocols for macroinvertebrate biomonitoring in Switzerland (Stucki, 2010). Eight kick-net samples per location were collected, pooled and stored in $80 \%$ ethanol prior to identification. Further details on the sampling procedure are described in Burdon et al. (2016). The data were used to calculate the trait-based Species At Risk (SPEAR) pesticide index (hereafter SPEAR index; Table S4.1), which is indicative of organic and especially pesticide contamination based on the presence or absence of taxa sensitive to pesticides (Liess \& Von Der Ohe, 2005). For the SPEAR calculation, the SPEAR Calculator v0.9.0 was used (SPEAR Calculator, 2016). The correlation between the mSPAF and SPEAR index was tested using three linear mixed-effects (LME) models. Further details on the model structure are described in Section S4.1 of the SI. 


\section{Results and Discussion}

\subsection{Exposure}

\subsubsection{General exposure to organic micropollutants in wastewater-impacted streams}

Of the 389 organic substances analyzed, 257 substances were measured at least once above the LOQ. All detected substances were found downstream, except for 3 pesticides and one biocide with only one detection upstream at concentrations close to the LOQ. In total 173 substances were detected upstream and 253 downstream. At all individual sites, more substances were detected at the downstream locations (60-167 substances) compared to the upstream locations (20-98 substances).

The mean detection frequency of the organic substances measured above the LOQ was around $30 \%$, ranging from $0.7 \%$ ( 2 detections over 276 samples) for the two insecticides chlorpyrifos and methylchlorpyrifos, to $96 \%$ (264 detections over 276 samples) for the corrosion inhibitor benzotriazole. The concentration ranges of the detected substances are shown in Figure 2 for the different substance groups for the upstream and downstream locations. Substances with highest maximum concentrations measured in the streams were terbutylazine for PPPs (3000 ng/L, Jun '13; median = $4.3 \mathrm{ng} / \mathrm{L})$, iopromide and gabapentin for pharmaceuticals (both 2000 ng/L, Jan '15, Jul \& Sep'14, median= 0 $\mathrm{ng} / \mathrm{L}$ ), diuron for biocides (220 ng/L, Jul '14, median = $4.4 \mathrm{ng} / \mathrm{L}$ ) and benzotriazole for corrosion inhibitors (3500 ng/L, Sep '14, median = $65 \mathrm{ng} / \mathrm{L}) .95 \%$ of the detected substances consisted to equal parts of pesticides and pharmaceuticals/narcotics. In agreement with several other studies (Fairbairn et al., 2016; Triebskorn et al., 2013), Figure 2 shows that the median values for PPPs remain in the same order of magnitude at the upstream and downstream locations. In contrast, the median of pharmaceuticals, and others even more, increases by almost one order of magnitude downstream of the WWTPs. The upstream concentrations of pharmaceuticals and household chemicals can be caused by releases through combined sewer overflows during rain events occurring before the sampling days, pipe leakages or wrong sewer connections (Joss et al., 2008). Single concentration values for all organic substances are reported in the SI (Table S2.3). 


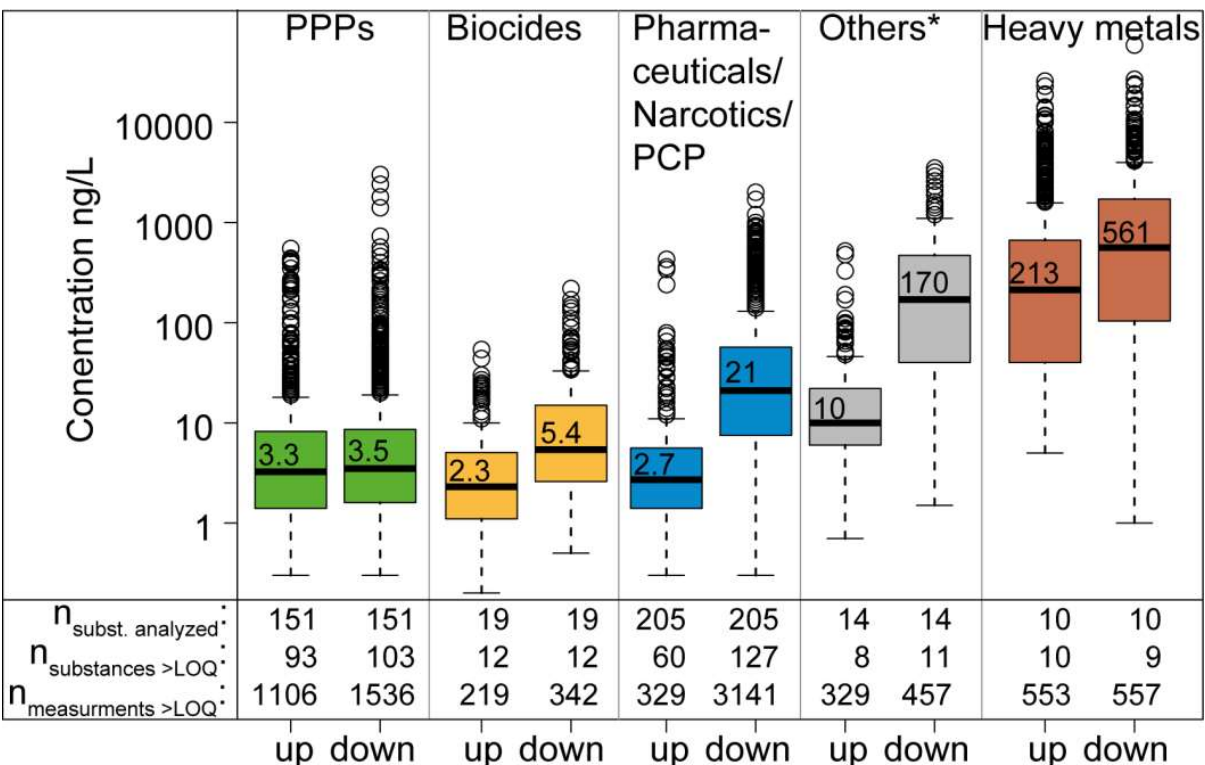

up down up down up down up down up down

Figure 2: Concentration levels of detected substances upstream (up) and downstream (down) of

WWTPs. Organic micropollutants were measured at sites 1 to 24 over 8 time points ( 2 time points with extended target screening). Heavy metals were only measured at sites 13 to 24 in the 6 bi-monthly samples from March 2014 to January 2015. LOQ = limit of quantification. *Others: corrosion inhibitors, food additives, caffeine, industrial chemicals. Numbers in boxplot indicate median value.

All 57 substances of the priority mixture were found at least once upstream and/or downstream and at least once in the effluent. Almost 50\% (28 substances) were detected at all sites (upstream and/or downstream) and in all effluents indicating their proper selection as exposure indicators. The average sum concentrations of the priority mixture ranged between $0.01-1.1 \mu \mathrm{g} / \mathrm{L}, 0.2-17 \mu \mathrm{g} / \mathrm{L}$ and $2.2-33 \mu \mathrm{g} / \mathrm{L}$ over the upstream, downstream and effluent locations, respectively.

\subsubsection{Influence of input pathways and land use on concentration pattern}

278 The results of the PCA show that the substances divide clearly into two groups with orthogonal loading 279 directions: pesticides (or substances with mainly diffuse input, e.g. agriculture) and pharmaceuticals 280 (or mainly wastewater originating substances) (Figure S2.1). This points towards an independence of 281 the input pathways and sources of these substance groups, which is in accordance with expectations. 282 Interestingly, this pattern is seen upstream as well as in the effluent, two independent sampling locations, indicating similar behavior of the concentration dynamics of the different substance groups for the two sampling locations.

When considering the different substance groups in the context of land use (Figure 1, Figure S2.2), PPPs showed a significant positive correlation with arable land for the upstream values, but not for the 
effluent (Figure S2.3). A slightly negative correlation was found with meadows and woods for the upstream concentrations. For any other substance group no significant correlations were found for the different land use types.

290

\subsubsection{Seasonality of micropollutant loads and concentration patterns}

292 Effluent loads were calculated using the average daily discharge of the WWTPs on the sampling dates, which were provided by the cantonal authorities and/or WWTP operators. The pharmaceutical loads in the effluent showed overall a decrease in summer (Figure 3), which could be due to higher temperatures and consequently higher degradation in the WWTP (Matamoros et al., 2016; Sun et al., 2014; Vieno et al., 2005). Additionally, a lower consumption rate of some pharmaceuticals such as antibiotics in summer could have an influence on the lower loads measured (Castiglioni et al., 2006; Petrie et al., 2015). For pesticides in general, no clear seasonality was observed (Figure S2.4). However, single substances, such as for example terbutylazine, showed a seasonal concentration pattern following the application period, indicating an input from agricultural land use also in the WWTP (Figure 3a). Regarding the heavy metals, no seasonal pattern was observed in the effluent. In addition, no considerable differences were observed between upstream, downstream and the effluent, with concentrations levels generally in the same order of magnitude (Table S2.4). The detection frequency for heavy metals was above $80 \%$, except for $\mathrm{Ag}$ and $\mathrm{Cd}$ with $1 \%$ and $28 \%$, respectively. 

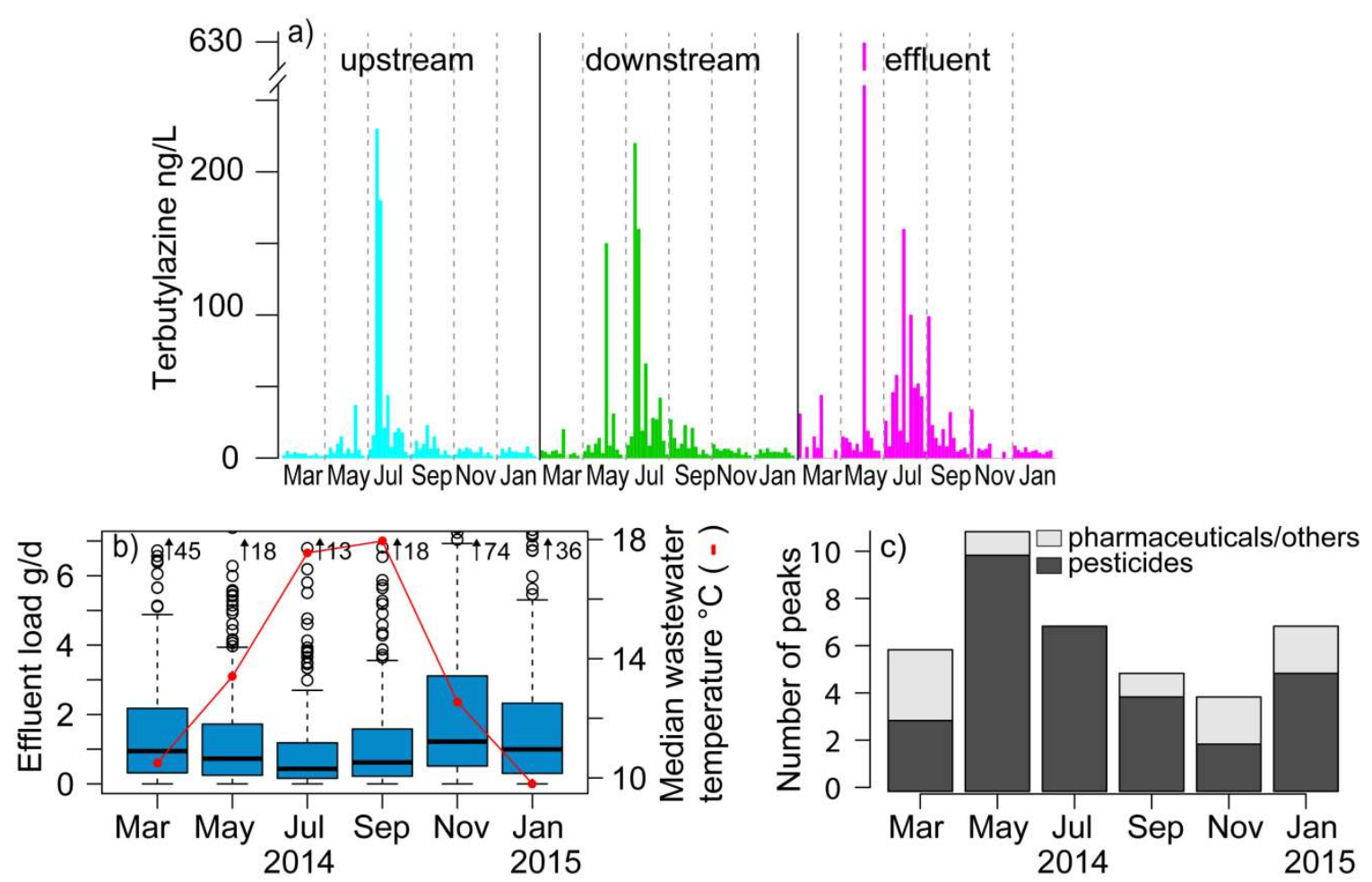

Figure 3: Seasonal patterns of a) terbutylazine concentration, plotted from site 13 to 24 for each month from March 2014 to January 2015, b) effluent loads of pharmaceuticals and personal care products ( $n=21$; boxplots; numbers in plot indicate maxima) with the median wastewater temperature (red line), and c) total number of concentration peaks (10 times higher than the average concentration), summed over upstream and downstream locations, for substances with at least $20 \%$ detection frequency. For this evaluation only substances of the priority mixture at the sites $13-24$ were considered. No data of the wastewater discharge and temperature was available for the WWTP Val-de-Ruz. Val-de-Ruz was excluded from the peak analysis, because of the wastewater input upstream.

\subsubsection{Concentration peaks during low flow conditions}

317 The highly dynamic pesticide concentrations, which are episodic and mainly occur during rain events, are only covered by chance when using grab samples. However, our sampling strategy targeted dry weather conditions, so that high concentration peaks can be attributed to unintentional spills rather than stormwater runoff. The occurrence of such elevated pesticide concentrations in effluent from WWTPs has been regularly reported in the literature (Gerecke et al., 2002, Müller et al., 2002, Wittmer et al., 2010) and also confirmed by measurements of Swiss cantonal authorities (U. Ochsenbein, pers. communication). In fact, looking at the concentration patterns of single substances (e.g. Figure 3a, Figure S2.4), single concentration peaks are still detectable despite the relatively few grab samples 
collected. To understand how often such high concentrations occur during low flow conditions and whether they may have an influence on the total risk, we defined concentrations 10 times higher than the average as peaks. However, peaks, as defined in our study, should not be regarded as equal to maximum concentrations, which can only be detected using highly resolved temporal concentration data. For the analysis, only substances with at least $20 \%$ detections were considered, and values below the LOQ were replaced with half the LOQ-values (Table S2.1).

In total, at over $80 \%$ of the sites (20 sites), 69 peaks of 40 substances were detected (including the extended screening data set). For 23 and 14 substances of the priority mixture, we observed 31 and 22 peaks downstream and upstream, respectively, with most of them detected in spring (Figure 3c). $70 \%$ of the 31 downstream peaks (22 peaks of 20 substances) showed higher concentrations downstream than upstream, which indicates an input from the WWTP (Table 1). With the extended target screening, three additional downstream peaks from the WWTP of single pesticides were observed. These findings are interesting especially regarding PPPs which constituted two-thirds of the peak substances, pointing towards a relevance of their release over the WWTP even during low flow conditions.

Due to the constraint of using only substances with $20 \%$ detection frequency, many insecticides were excluded because of their generally low concentrations close to the LOQ. However, dimethoate, pirimicarb and thiacloprid were all substances that showed high single inputs from the WWTP with peaks downstream of up to $100 \mathrm{ng} / \mathrm{L}$ while no or lower detections were observed upstream (Figure S2.4).

Table 1: Substances with peaks detected downstream (10-fold higher than the average downstream concentration) which had a detection frequency of at least $20 \%$. Priority mixture analyzed over eight time points above dashed lines and the additional substances measured for June 2013 and May 2014 below dashed lines.

\begin{tabular}{|c|c|c|c|c|c|c|c|c|}
\hline Substance & $\begin{array}{l}\text { Sub- } \\
\text { stance } \\
\text { group }^{a}\end{array}$ & \#peaks $_{\text {down }}$ & $\begin{array}{c}\text { \#peaks } s_{\text {down }} \\
\text { where } \\
c_{\text {down }}>c_{\text {up }}\end{array}$ & $\begin{array}{c}\text { Conc. } \\
\text { peak }_{\text {down }} \\
\text { where } \\
\text { C down }_{\text {do }} \text { c }_{\text {up }} \\
\text { (ng/L) }\end{array}$ & $\begin{array}{c}\text { PAF of peak } k_{\text {down }} \\
\text { where } \\
\mathbf{c}_{\text {down }}>\mathbf{c}_{\text {up }}{ }^{b} \\
(\%)\end{array}$ & $\begin{array}{c}\text { Total } \\
\text { msPAF } \\
(\%)\end{array}$ & Site $^{c}$ & Date \\
\hline Atrazine & ppp (h) & 1 & 1 & 99 & 0.03 & 0.05 & 17 & Mar'14 \\
\hline Azoxystrobin & $\operatorname{ppp}(f)$ & 2 & 1 & 73 & $<0.0001$ & 0.05 & 6 & Jun'13 \\
\hline
\end{tabular}




\begin{tabular}{|c|c|c|c|c|c|c|c|c|}
\hline Chlortoluron & ppp (h) & 2 & 0 & & & & & \\
\hline Cyproconazole & $\operatorname{ppp}(\mathrm{f})$ & 1 & 1 & 17 & $<0.0001$ & 0.8 & 21 & May'14 \\
\hline Cyprodinil & $\operatorname{ppp}(f)$ & 1 & 1 & 8.9 & $<0.0001$ & 0.8 & 21 & May'14 \\
\hline Diazinon & ppp (i) & 1 & 1 & 130 & 0.890 & 0.9 & 8 & Jun'13 \\
\hline Epoxyconazole & $\operatorname{ppp}(f)$ & 1 & 0 & & & & & \\
\hline Isoproturon & $\mathrm{ppp}(\mathrm{h})$ & 1 & 1 & 59 & 0.0025 & 0.3 & 19 & Jul'14 \\
\hline Metribuzin & ppp (h) & 2 & 1 & 37 & 0.0001 & 0.2 & 13 & Nov'14 \\
\hline Penconazole & $\operatorname{ppp}(f)$ & 1 & 1 & 730 & $<0.0001$ & 0.2 & 4 & Jun'13 \\
\hline Propamocarb & $\operatorname{ppp}(f)$ & 2 & 1 & 510 & $<0.0001$ & 0.9 & 8 & Jun'13 \\
\hline Propiconazole & $\operatorname{ppp}(f)$ & 3 & 0 & & & & & \\
\hline Simazine & ppp (h) & 1 & 1 & 39 & $<0.0001$ & 0.1 & 20 & Sep'14 \\
\hline Tebuconazole & $\operatorname{ppp}(f)$ & 1 & 1 & 1800 & 0.0001 & 0.2 & 19 & Mar'14 \\
\hline Terbutylazine & ppp (h) & 1 & 1 & 3000 & 0.39 & 0.5 & 1 & Jun'13 \\
\hline Bentazon & ppp (h) & 1 & 0 & & & & & \\
\hline Dimethenamid & ppp (h) & 1 & 0 & & & & & \\
\hline Linuron & ppp (h) & 1 & 1 & 110 & 0.012 & 0.50 & 6 & Jun'13 \\
\hline Metamitron & ppp (h) & 1 & 1 & 210 & - & 0.80 & 21 & May'14 \\
\hline $\begin{array}{l}\text { Metamitron- } \\
\text { Desamino }\end{array}$ & ppp (h) & 1 & 0 & & & & & \\
\hline Metolachlor & $\mathrm{ppp}(\mathrm{h})$ & 1 & 1 & 570 & 0.0005 & 1.60 & 19 & May'14 \\
\hline Prosulfocarb & ppp (h) & 1 & 0 & & & & & \\
\hline All PPPs & & 28 & 15 & & & & & \\
\hline Carbendazim & $b(f)$ & 2 & 2 & $99 ; 89$ & $0.0001 ;<0.0001$ & $0.2 ; 0.06$ & 13 & Sep'14,Jan'15 \\
\hline Diuron & b (h) & 1 & 1 & 220 & 0.035 & 0.1 & 21 & Jul'14 \\
\hline Terbutryn & b (h) & 1 & 1 & 110 & 0.13 & 0.5 & 13 & Mar'14 \\
\hline All Biocides & & 4 & 4 & & & & & \\
\hline Amisulprid & ph & 1 & 1 & 310 & - & 0.1 & 15 & Nov'14 \\
\hline Iopromid & $\mathrm{ph}$ & 2 & 2 & $2000 ; 1700$ & - & $0.02,0.03$ & $17 ; 20$ & Jan'15,Nov'14 \\
\hline Torasemid & $\mathrm{ph}$ & 1 & 1 & 160 & - & 0.2 & 19 & Mar'14 \\
\hline Vildagliptin & ph & 1 & 1 & 120 & - & 0.2 & 19 & Mar'14 \\
\hline Sulfamethazine & ph & 1 & 0 & & & & & \\
\hline All Pharmaceuticals & & 6 & 5 & & & & & \\
\hline Caffeine & $\mathrm{t}$ & 1 & 1 & 490 & $<0.0001$ & 0.002 & 24 & Jan'15 \\
\hline All Substances & & 38 & 25 & & & & & \\
\hline
\end{tabular}

'Site code as in Table S1.1 of the SI

\section{$356 \quad 3.2$ Toxic pressure on aquatic organisms}

357 3.2.1 Toxicity data set

358 In total, 165 organic substances had available toxicity data for the construction of a SSD. The low-

359 quality data $(n=41)$ was excluded because of greater uncertainties, resulting in 124 substances used

360 for the msPAF calculations. Of the 124 organic substances, 94 were measured at least once above 
the LOQ. For all heavy metals toxicity data was available; three ( $\mathrm{Co}, \mathrm{Fe}, \mathrm{Mn})$ were categorized as low quality data. Very little toxicity data was available for pharmaceuticals, and that which was available was mostly of low quality, limiting the interpretation regarding their risk. Nevertheless, the toxicity distribution of the available data shows that the majority of the pharmaceuticals are less toxic compared to the pesticides (Figure 4). For the 94 detected substances 55 different TMoA were assigned. Regarding the priority mixture, 36 of the 46 substances with available toxicity data were of good quality, which were categorized into 23 different TMOA. The toxicity distribution of the priority mixture covered a similar range as the whole data set $( \pm 0.2 \mu \mathrm{g} / \mathrm{L}$ of the percentiles, see Figure 4$)$.

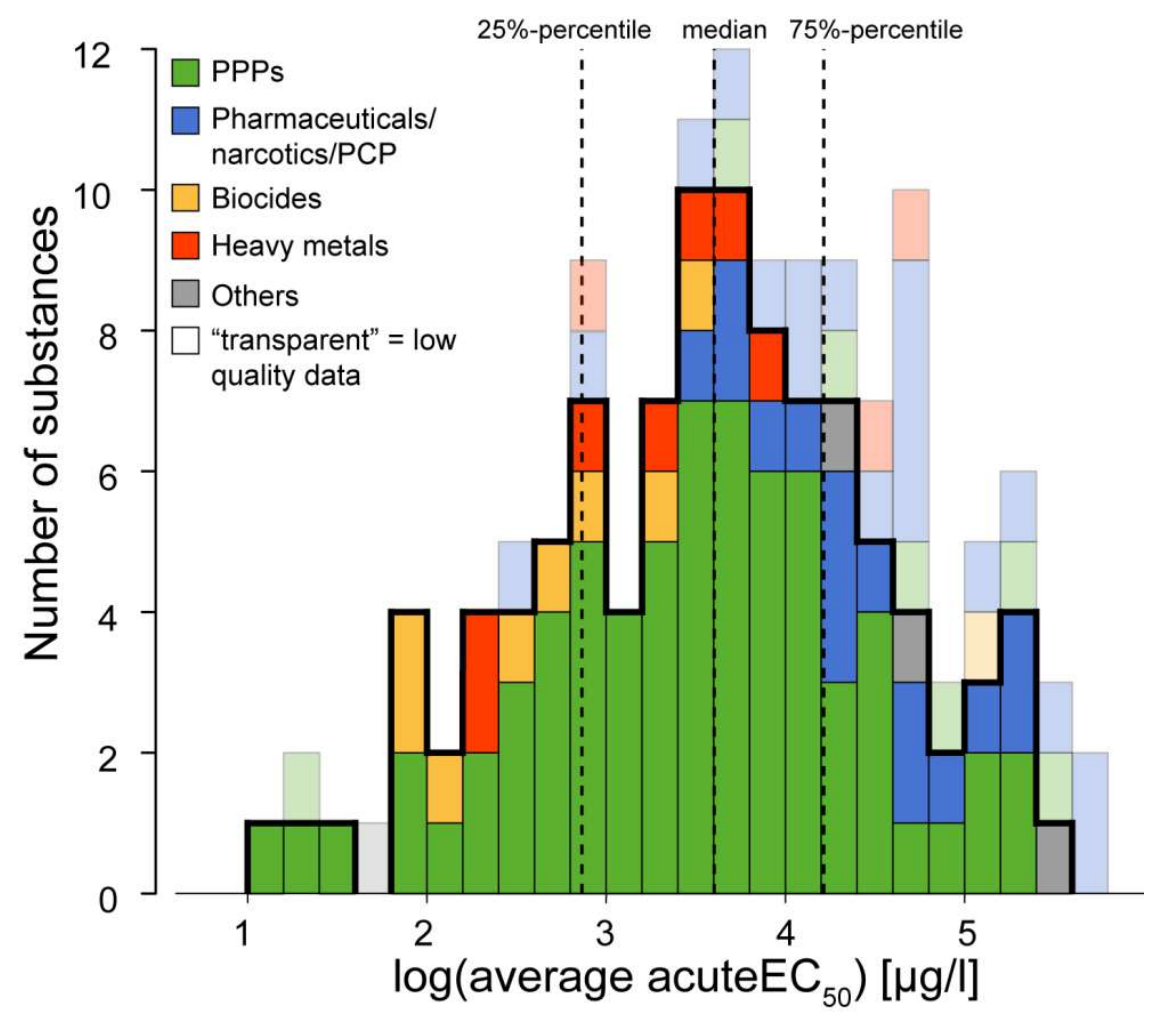

Figure 4: Distribution of toxicity data for substances measured at least once above the limit of quantification ( $n=101,94$ organic substances +7 heavy metals). Percentiles are calculated excluding low quality data. PPPs: Plant Protection Products, PCP: Personal Care Products, Others: Corrosion inhibitors, caffeine, sucralose.

\subsubsection{Acute toxic pressure: comparison of msPAF and EQS}

Over the 24 sites, the acute toxic pressure on aquatic organisms (msPAF) is relatively low, in the range of $0 \%$ to $2.1 \%$ (Figure 5), and thus below the generally accepted threshold for acceptable risk of $5 \%$ of the species (Posthuma et al., 2002; Smetanová et al., 2014). A study investigating the risk of $\sim 300$ organic substances in Dutch rivers and effluents also found very low toxic pressures, with a 
maximum of $0.3 \%$, which highlights that low acute toxic pressures in rivers may be a future trend because of the better removal processes and regulating measures taken at the source (Hamers et al., 2016). In contrast, the $R Q_{\text {mix }}$ using MAC-EQSs was higher than 1 for $35 \%$ and $2 \%$ of the downstream and upstream samples, respectively (Figure 5). As the $R Q_{\text {mix }}$ has a precautionary purpose, exceedances of 1 indicate that negative impacts on aquatic organisms cannot be excluded.

The highest toxic pressures were predicted at downstream sites, except for the maximal toxic pressure which was found at Messen upstream in June 2013 using the extended target screening. The high acute toxic pressure there ( $2.1 \%$ of affected species) is mainly due to the herbicide triflusulfuronmethyl, which at $41 \mathrm{ng} / \mathrm{L}$ had already a great impact on the risk due to its high toxicity. In this particular case, the msPAF would be reduced to $0.14 \%$ when considering only the priority mixture. All msPAF values are reported in Tables S3.3 and S3.4 of the SI.

The discrepancy between the rather low toxic pressure predicted with the msPAF and the large exceedances of the MAC-EQSs are expected because of the different purposes of the two approaches (estimation of observable effects in the field vs. precautionary risk threshold). Nevertheless, other factors can contribute to these differences. Due to the use of acute toxicity values for the mSPAF, which are more robust than chronic data, the sub-lethal (chronic) effects on aquatic organisms may not be fully detected (Carafa et al., 2011). It has been shown that the acute msPAF may therefore underestimate the observations in the field (Smetanová et al., 2014). This depends as well on the sampling strategy, as the grab samples used may not reflect the actual levels of contamination.

402 


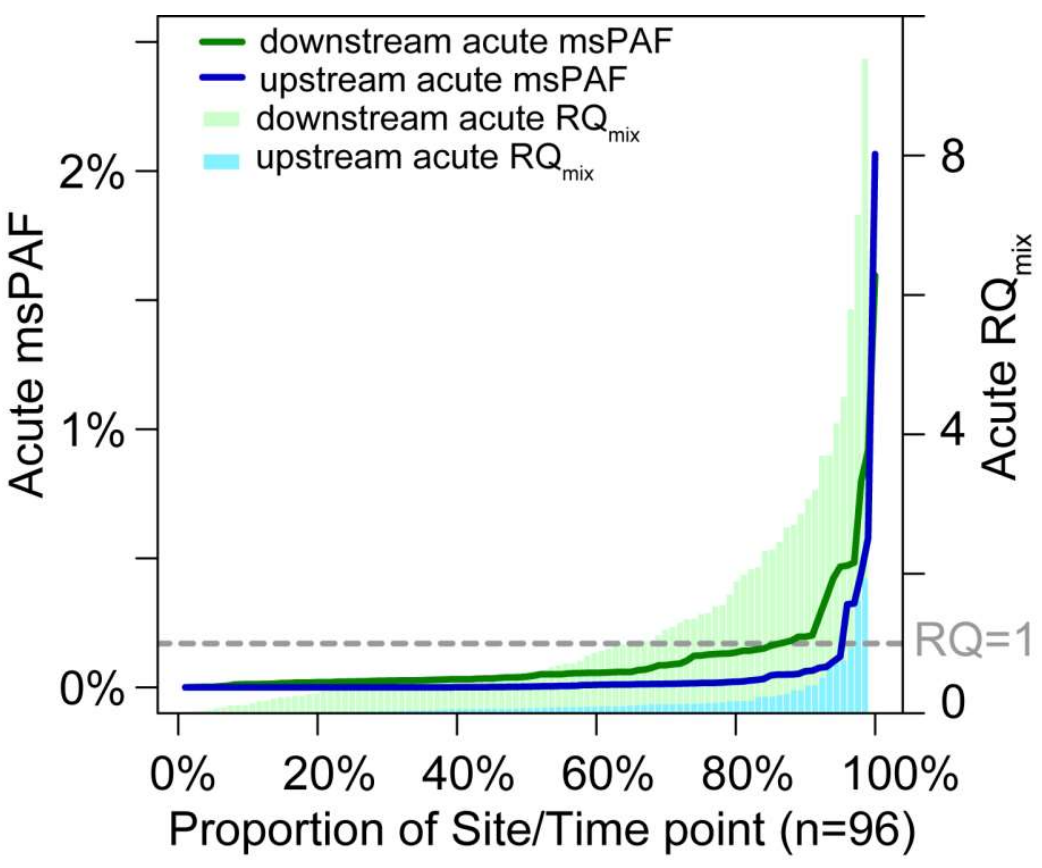

Figure 5: Acute msPAFs and RQs plotted against the proportion of site/time point (=sample).

405

\subsubsection{Risk driving substances}

In general, only a few single substances were the main drivers of the acute risk (Figure 6), which was also observed in other studies (e.g. Backhaus \& Karlsson, 2014). In most cases the Top5 substances of the msPAFs for each site and time point explained already the total predicted risk. They were defined for each site and time point as the five substances with the highest PAF, under the condition that the PAF was greater or equal to $0.0001 \%$. Three substances - diclofenac, diazinon and clothianidin - were clearly the most substantial drivers of the risk: $50 \%$ to $90 \%$ of the concentration values contributed to the Top5 of the total msPAFs over the different sites and time points. By removing these three substances from the data set, the acute toxic pressure decreased by more than $60 \%$ for almost $80 \%$ of all samples when only msPAF values greater than $0.001 \%$ were considered (Figure S3.1, S3.2). For substances with at least $20 \%$ overall detections, additional calculations were performed using half the LOQ-values for values measured below the LOQ. No large differences were observed in the msPAF results (Figure S3.1), underlining the importance of the influence of single substances.

Overall, it seems that the msPAF is more driven by substances with above average toxicity than by substances with above average concentrations. Half of the 26 Top 5 substances are part of the $25 \%$ most toxic substances in the data set (Figure S3.1). This also highlights the importance of pesticides 
and especially insecticides, which are generally much more toxic to aquatic organisms than pharmaceuticals. Underscoring this point, 19 of the 26 Top5 substances are plant protection products. The study on the ecotoxicological risk in Spanish rivers supports the importance of pesticides as major contributors to the overall risk (Kuzmanović et al., 2015). However, we used acute toxicity values and it is known that several pharmaceuticals (e.g. diclofenac) have high acute to chronic ratios, thus reducing the calculated risk of pharmaceuticals when only using acute values. Despite this, some pharmaceuticals also appeared as relevant effect contributors, such as diclofenac, clarithromycin or naproxen, although a definite statement of the real impact of pharmaceuticals is limited due to the restricted availability of effect data. However, the analysis of the RQmix (based on MAC-EQSs) also showed that the risk was mainly driven by a few single substances, with pesticides, such as for example diazinon and diuron, having the greatest influence. Unfortunately, no MAC-EQSs are available for diclofenac and clothianidin, so as to compare with the most influential drivers of the msPAF (see EC, 2011).

In some cases high concentrations also substantially contributed to the total risk. Of the 69 concentration peaks detected overall, 52 were from substances with available toxicity data (27 substances) of which 25\% (13 peaks) appeared in the Top5 of the msPAF. Seven of the downstream peaks had higher concentrations downstream than upstream, pointing towards the WWTP as source (Table 1). As more of these peaks in higher concentrations have to be expected than covered with our sampling strategy, an increase of the predicted risk due to high concentrations is expected. This is supported by considering also substances with less than $20 \%$ detection frequency, which were excluded for the peak analysis: for example, the aforementioned elevated concentrations of the insecticides dimethoate, pirimicarb and thiacloprid detected downstream appear all in the Top5 of the msPAF.

For matter of completeness, the msPAF was also calculated including the analyzed heavy metals as previous studies described their potential influence on the risk (Carafa et al., 2011; Kuzmanović et al., 2015). In our case, the heavy metals played only a minor role: $\mathrm{Zn}$, at seven downstream and one upstream site, and $\mathrm{Ni}$ at only one upstream site, were part of the Top5 substances and contributed with fractions of $0.01-0.05 \%$ to the total msPAF (Figure S3.1). 
a) Example: Aadorf downstream, May 2014

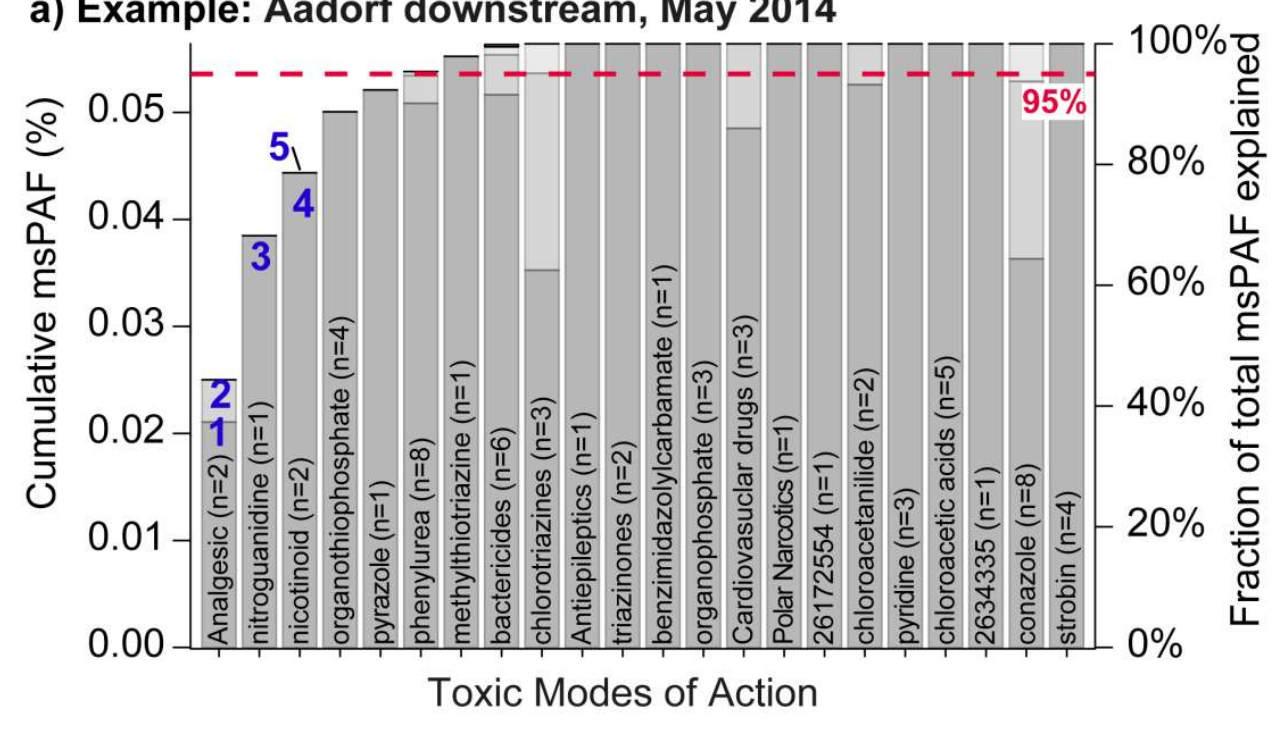

b) Number of substances explaining total msPAF over all sites

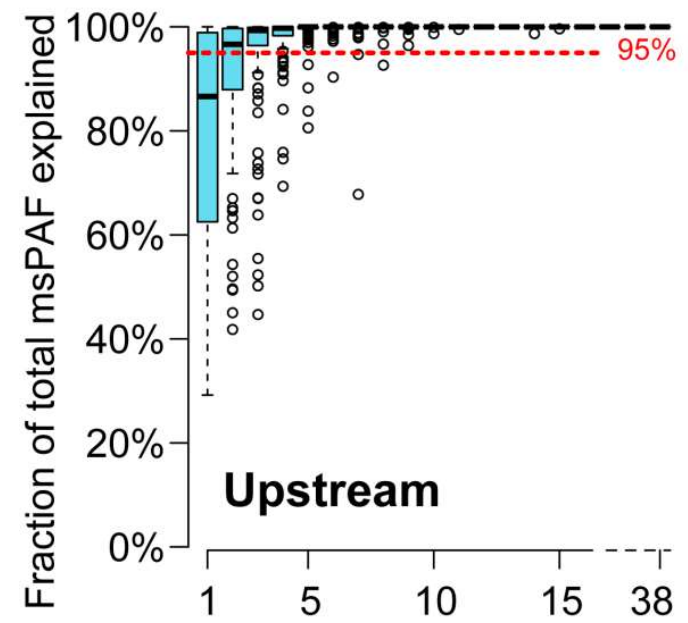

Number of substances

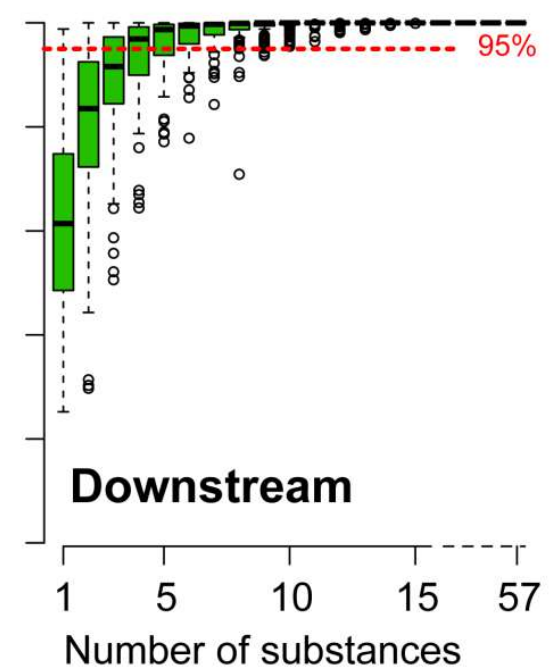

Figure 6: Exemplary cumulative distribution of a) the msPAF for Aadorf downstream in May 2014, and

b) the cumulative fraction of the total msPAF explained by single substances at all sites for upstream and downstream. (a): the single bars correspond to the msPAF calculated using concentration addition for each TMoA (the stacked bars indicate the single substances within one TMOA). Iterative calculation of the total msPAF was achieved using response addition. Division of single substances within each TMoA was done by using the proportions of the hazard units (effect concentration over measured concentration). Number of substances of each TMoA in brackets. (b): The plot was constructed using the cumulative distributions of the single TMoA for each sample (see plot a) ). Therefore, for each sample the msPAFCA of the single TMoA was calculated using concentration addition and ranked in decreasing order. Within each TMoA the substances were sorted in decreasing order by their hazard unit. The whole substance list was then ranked, from 1 to $n$ substances contributing to the total 
msPAF, as it is shown in (a) for the first 5 substances: diclofenac, naproxen, clothianidin, imidacloprid, flonicamid (blue numbers).

\subsubsection{Extended screening vs. priority mixture}

The msPAF showed very similar results for the extended screening data set and the priority mixture, where 94 and 36 detected substances were included, respectively (Figure S3.3). Moschet et al. (2014) showed that a well-defined substance selection for pesticides predicts almost the same risk level as would be predicted using the whole list of registered pesticides in areas dominated by agricultural land uses. In our study, a total of 26 substances appeared in the Top5 of the msPAF of which only three substances, triflusulfuron-methyl, naproxen, and irgarol, are not part of the priority mixture. Overall, regarding the substances with the greatest influence on the mSPAF, no major differences could be detected using the screening or the priority mixture. These findings clearly highlight the substances used in the priority mixture not only being good indicators for exposure but also for risk.

Including all the available toxicity data (with low quality data; see Section S3.1 of the SI), the msPAF was substantially increased when the extended data set was used as opposed to the priority mixture (Figure S3.4). However, two substances, furosemide and desethyl-atrazine, were responsible for this difference. Furosemide shows a moderate toxicity but a relatively high standard deviation of the SSD. Substances with high standard deviations can have a large impact on the risk even at low concentrations, thus often leading to an overestimation of the risk (Gregorio et al., 2013). Overall, this highlights on one hand the selection of toxicity data as a critical factor, and on the other hand demonstrates the potential influence of single substances in driving the total risk.

\subsubsection{Effects on macroinvertebrates}

The risk indicators described above were compared to macroinvertebrate data collected at the same sites. Results from the 2013 sites showed that the macroinvertebrate community downstream seemed to be influenced by discharged wastewater. A larger fraction of wastewater at the downstream locations was correlated with a larger decrease from upstream to downstream in taxa sensitive to pesticides as indicated by the SPEAR index (Burdon et al., 2016). Because the SPEAR index is an indicator of sensitivity to pesticides (Liess \& Von Der Ohe, 2005), this correlation suggested the possible widespread influence of these substances in treated wastewater (Burdon et al., 2016). 
Furthermore, at upstream sampling locations, the SPEAR index was strongly negatively correlated with the fraction of arable land in the catchment (Burdon et al., 2016; Stamm et al., 2016). Thus, quantifying risk factors through analysis of chemical data and linking with observed influences on stream macroinvertebrates is a logical step in determining the scale of this environmental problem.

Our risk assessment suggests an overall good agreement with the observed effects on stream macroinvertebrates, where pesticides seemed to be the main drivers of the risk at both upstream and downstream locations. This was shown by the significant correlation of the msPAF values with the SPEAR index across all 24 sites $\left(\mathrm{t}_{23}=-3.759, \mathrm{p}<0.001\right.$; Figure 7 ; Table S4.2). A similar correlation was observed when considering only pesticides for the mSPAF calculation $\left(t_{23}=-3.778, p<0.001\right)$, while no significant correlation was seen for the rest of the substances $\left(t_{22}=-0.349, p=0.730\right)$. The significant relationship between pesticide risk and macroinvertebrate sensitivity to pesticides was observed despite household chemicals constituting the highest loads at downstream locations, suggesting that toxicity and not total concentrations is a key determinant of micropollutant impacts in mixed land use environments. Similar results were found for Spanish rivers, where an increase in toxic pressure was linked to observed losses of sensitive macroinvertebrate species (Kuzmanović et al., 2015). Our findings and those of Kuzmanović et al. (2015) clearly highlight the validity of approaches linking chemical data and risk predictions in detecting realized toxic effects that are observed in the field. Whilst the use of both methods is optimal, the correlation between risk factors and pesticide sensitivity suggests either approach is useful for detecting pesticide effects in the environment.

a) all data

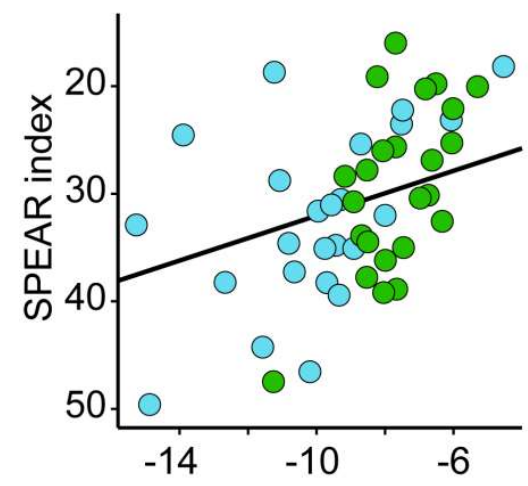

log median msPAF b) only pesticides

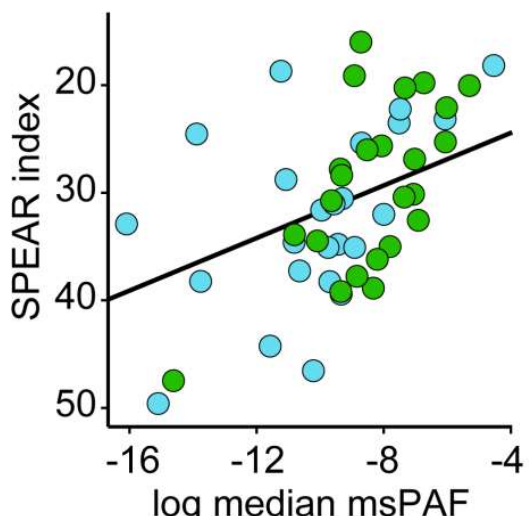

c) without pesticides

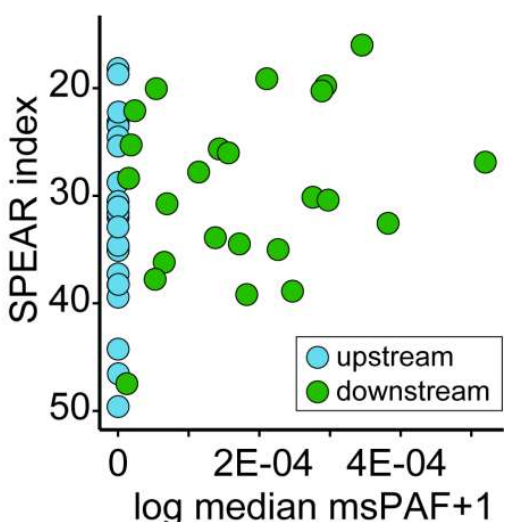


Figure 7: Relationship between the SPEAR index and the mSPAF a) for all data $\left(\mathrm{t}_{23}=-3.759\right.$, $\mathrm{p}<0.001), \mathrm{b})$ only for pesticides $\left(\mathrm{t}_{23}=-3.778, \mathrm{p}<0.001\right)$, and $\left.\mathrm{c}\right)$ without $\left(\mathrm{t}_{22}=-0.349, \mathrm{p}=0.730\right)$, at all 24 sites. Relationships were tested using linear mixed-effects models where the fixed effects included "msPAF" and "Location" (only c) ), and the random effect was "Site". The axes of the SPEAR index have been reversed to aid interpretability.

However, as the toxicity data for pharmaceuticals is very limited compared to the pesticide data, our interpretation is restricted as pharmaceuticals from the WWTP might also have an impact on aquatic organisms, especially fish (Ankley \& Villeneuve, 2015; Brodin et al., 2013). Behavioral changes, such as feeding rate, mating success and parental care have been reported for fish and it has been shown that for example the psychiatric drug oxazepam elicited effects towards perch but not towards damselflies (Brodin et al., 2014). This highlights on the one hand the need for more studies on effects of pharmaceuticals and on the other hand the difficulty of the proper use and interpretation of the effect data.

\section{Conclusions}

- We showed that a multitude of micropollutants are regularly released to the environment from WWTPs during low flow conditions, with occasional concentration peaks resulting mainly from pesticides. Analysis of the different substance groups showed a differentiation of input sources and pathways (e.g. agriculture and households) for pesticides and pharmaceuticals, as well as a correlation of arable land use with the concentrations upstream of plant protection products.

- While household chemicals constituted the highest loads and were regularly released from the WWTPs, pesticides were discharged only during episodic events, meaning concentration peaks are poorly represented when using only grab samples. Nevertheless, the predicted risk seemed to be clearly dominated by pesticides (apart from diclofenac), although interpretation regarding pharmaceuticals is limited due to a paucity of toxicity data.

- The risk was clearly driven by a few single substances, independent of the data set used (extended screening or priority mixture). Thus, the priority mixture was found to be both a good exposure and risk indicator for wastewater-impacted streams during low flow conditions.

- Despite the overall very low predicted acute risk (msPAF $<5 \%$ ), observed effects on macroinvertebrates from field biomonitoring (SPEAR index) showed a significant positive 
correlation. The findings clearly support the importance of pesticides in wastewater-impacted streams also during low flow conditions.

- The importance of pesticides regarding risk towards aquatic organisms also during low flow conditions is expected to be typical for catchments where urban and agricultural land use types co-occur as it is the case for many European countries.

557

Acknowledgements

559 SOLUTIONS is supported by the European Union Seventh Framework Programme (FP7-ENV-2013-

560 two-stage Collaborative project) under grant agreement number 603437 . Field and analytical work

561 within the Ecolmpact project was funded by Eawag and the Swiss Federal Office for the Environment

562 (FOEN). The authors thank the whole Ecolmpact team and especially Johanna Otto, Fabian Deuber, 563 Jonas Mechelke, Philipp Longrée (all Eawag) for their support in the laboratory, David Kistler (Eawag)

564 for the analysis of the heavy metals and Adriano Joss, Rosi Siber, Christoph Ort (all Eawag) for the 565 support in the site selection. The cantonal authorities (AG, BE, SO, TG, ZH) as well as the operators 566 of the WWTPs Aadorf and Zullwil are thanked for providing discharge and temperature data. Jennifer Schollée (Eawag) is acknowledged for improving the manuscript. 


\section{References}

572

Altenburger, R., Ait-Aissa, S., Antczak, P., Backhaus, T., Barceló, D., Seiler, T. B., Brion, F., Busch, W., Chipman, K., López de Alda, M., Umbuzeiro, G. A., Escher, B. I., Falciani, F., Faust, M., Focks, A., Hilscherova, K., Hollender, J., Hollert, H., Jäger, F., Jahnke, A., Kortenkamp, A., Krauss, M., Lemkine, G. F., Munthe, J., Neumann, S., Schymanski, E. L., Scrimshaw, M., Segner, H., Slobodnik, J., Smedes, F., Kughathas, S., Teodorovic, I., Tindall, A. J., Tollefsen, K. E., Walz, K. H., Williams, T. D., Van den Brink, P. J., van Gils, J., Vrana, B., Zhang, X. W., \& Brack, W., 2015. Future water quality monitoring - Adapting tools to deal with mixtures of pollutants in water resource management. Science of the Total Environment, 512, 540-551. doi:10.1016/j.scitotenv.2014.12.057

Ankley, G. T., \& Villeneuve, D. L., 2015. Temporal Changes in Biological Responses and Uncertainty in Assessing Risks of Endocrine-Disrupting Chemicals: Insights from Intensive Time-Course Studies with Fish. Toxicological Sciences, 144 (2), 259-275. doi:10.1093/toxsci/kfu320

Backhaus, T., \& Karlsson, M., 2014. Screening level mixture risk assessment of pharmaceuticals in STP effluents. Water Research, 49, 157-165. doi:10.1016/j.watres.2013.11.005

BAFU, Bundesamt für Umwelt, 2013. Swiss stream-based catchment classification GAB-EZGG-CH (in German). http://www.bafu.admin.ch/wasser/13462/13496/15866/index.html?lang=en (05.07.2016)

Barber, L. B., Keefe, S. H., Brown, G. K., Furlong, E. T., Gray, J. L., Kolpin, D. W., Meyer, M. T., Sandstrom, M. W., \& Zaugg, S. D., 2013. Persistence and Potential Effects of Complex Organic Contaminant Mixtures in Wastewater-Impacted Streams. Environmental Science and Technology, 47 (5), 2177-2188. doi:10.1021/es303720g

BFS, Bundesamt für Statistik, 2014. Land use statistics after nomenclature 2004 - Standard (in German). http://www.bfs.admin.ch/bfs/portal/de/index/dienstleistungen/geostat/datenbeschreibung/areal statistik 2004.html (05.07.2016)

Bliss, C. I., 1939. The toxicity of poisons applied jointly. Annals of Applied Biology., 26, 585-615.

Brodin, T., Fick, J., Jonsson, M., \& Klaminder, J., 2013. Dilute Concentrations of a Psychiatric Drug Alter Behavior of Fish from Natural Populations. Science, 339 (6121), 814-815. doi:10.1126/science. 1226850 
601

602

603

604

605

606

607

608

609

610

611

612

613

614

615

616

617

618

619

620

621

622

623

624

625

626

627

628

629

630

Brodin, T., Piovano, S., Fick, J., Klaminder, J., Heynen, M., \& Jonsson, M., 2014. Ecological effects of pharmaceuticals in aquatic systems-impacts through behavioural alterations. Philosophical Transactions of the Royal Society B-Biological Sciences, 369 (1656). doi:10.1098/rstb.2013.0580

Burdon, F. J., Reyes, M., Alder, A. C., Joss, A., Ort, C., Räsänen, K., Jokela, J., Eggen, R. I. L., \& Stamm, C., 2016. Environmental context and magnitude of disturbance influence traitmediated community responses to wastewater in streams. Ecology and Evolution, 6 (12), 3923-3939. doi:10.1002/ece3.2165

Carafa, R., Faggiano, L., Real, M., Munné, A., Ginebreda, A., Guasch, H., Flo, M., Tirapu, L., \& von der Ohe, P. C., 2011. Water toxicity assessment and spatial pollution patterns identification in a Mediterranean River Basin District. Tools for water management and risk analysis. Science of the Total Environment, 409 (20), 4269-4279. doi:10.1016/j.scitotenv.2011.06.053

Castiglioni, S., Bagnati, R., Fanelli, R., Pomati, F., Calamari, D., \& Zuccato, E., 2006. Removal of pharmaceuticals in sewage treatment plants in Italy. Environmental Science and Technology, 40 (1), 357-363. doi:10.1021/es050991m

Couperus, N. P., Pagsuyoin, S. A., Bragg, L. M., \& Servos, M. R., 2016. Occurrence, distribution, and sources of antimicrobials in a mixed-use watershed. Science of the Total Environment, 541, 1581-1591. doi:10.1016/j.scitotenv.2015.09.086

De Zwart, D. (2002). Observed Regularities in Species Sensitivity Distributions. In L. Posthuma, G. W. Suter, \& T. P. Traas (Eds.), Species sensitivity distributions in ecotoxicology (pp. 133-154). Boca Raton: Lewis.

De Zwart, D., \& Posthuma, L., 2005. Complex mixture toxicity for single and multiple species: Proposed methodologies. Environmental Toxicology and Chemistry, 24 (10), 2665-2676. doi:Doi 10.1897/04-639r.1

De Zwart, D., Posthuma, L., Gevrey, M., von der Ohe, P. C., \& de Deckere, E., 2009. Diagnosis of ecosystem impairment in a multiple-stress context--how to formulate effective river basin management plans. Integrated Environmental Assessment and Management, 5 (1), 38-49.

EC, European Commission, 2011. Common Implementation Strategy for the Water Framework Directive (2000/60/EC). Guidance Document No. 27: Technical Guidance For Deriving Environmental Quality Standards. 
Ecotox Centre Eawag-EPFL. (2016). Proposals for Acute and Chronic Quality Standards. http://www.ecotoxcentre.ch/expert-service/quality-standards/proposals-for-acute-and-chronicquality-standards/ (05.07.2016)

Eggen, R. I., Hollender, J., Joss, A., Schärer, M., \& Stamm, C., 2014. Reducing the discharge of micropollutants in the aquatic environment: the benefits of upgrading wastewater treatment plants. Environmental Science and Technology, 48 (14), 7683-7689. doi:10.1021/es500907n

Englert, D., Zubrod, J. P., Schulz, R., \& Bundschuh, M., 2015. Variability in ecosystem structure and functioning in a low order stream: Implications of land use and season. Science of the Total Environment, 538, 341-349. doi:10.1016/j.scitotenv.2015.08.058

EU, 2013. EU Directive 2013/39/EU of the European Parliament and of the Council of 12 August 2013 amending Directives 2000/60/EC and 2008/105/EC as regards priority substances in the field of water policy Text with EEA relevance. http://eurlex.europa.eu/LexUriServ/LexUriServ.do?uri=OJ:L:2013:226:0001:0017:EN:PDF (05.07.2016)

Fairbairn, D. J., Arnold, W. A., Barber, B. L., Kaufenberg, E. F., Koskinen, W. C., Novak, P. J., Rice, P. J., \& Swackhamer, D. L., 2016. Contaminants of Emerging Concern: Mass Balance and Comparison of Wastewater Effluent and Upstream Sources in a Mixed-Use Watershed. Environmental Science and Technology, 50 (1), 36-45. doi:10.1021/acs.est.5b03109

Gerecke, A. C., Schärer, M., Singer, H. P., Müller, S. R., Schwarzenbach, R. P., Sägesser, M., Ochsenbein, U., \& Popow, G., 2002. Sources of pesticides in surface waters in Switzerland: pesticide load through waste water treatment plants-current situation and reduction potential. Chemosphere, 48 (3), 307-315. doi:10.1016/S0045-6535(02)00080-2

Gómez, M. J., Herrera, S., Solé, D., García-Calvo, E., \& Fernández-Alba, A. R., 2012. Spatio-temporal evaluation of organic contaminants and their transformation products along a river basin affected by urban, agricultural and industrial pollution. Science of the Total Environment, 420, 134-145. doi:10.1016/j.scitotenv.2012.01.029

Gregorio, V., Chèvre, N., \& Junghans, M., 2013. Critical issues in using the common mixture toxicity models concentration addition or response addition on species sensitivity distributions: A theoretical approach. Environmental Toxicology and Chemistry, 32 (10), 2387-2395. doi:10.1002/etc. 2320

Hamers, T., Legradi, J., Zwart, N., Smedes, F., de Weert, J., van den Brandhof, E.-J., van de Meent, D., \& de Zwart, D., 2016. Time-Integrative Passive sampling combined with Toxicity Profiling 

(TIPTOP): an effect-based strategy for cost-effective chemical water quality assessment. Final report of the LRI-ECO23 project.

Herlyn, A., \& Maurer, M., 2007. Status, costs and investment needs of the Swiss wastewater disposal (in German). Gas Wasser Abwasser (gwa), 3.

Huntscha, S., Singer, H. P., McArdell, C. S., Frank, C. E., \& Hollender, J., 2012. Multiresidue analysis of 88 polar organic micropollutants in ground, surface and wastewater using online mixed-bed multilayer solid-phase extraction coupled to high performance liquid chromatography-tandem mass spectrometry. Journal of Chromatography A, 1268, 74-83. doi:10.1016/j.chroma.2012.10.032

Joss, A., Siegrist, H., Ternes, T. A., 2008. Are we about to upgrade wastewater treatment for removing organic micropollutants? Water Science \& Technology, 57.2, 251-255, doi: $10.2166 /$ wst.2008.825

Junghans, M., Backhaus, T., Faust, M., Scholze, M., \& Grimme, L. H., 2006. Application and validation of approaches for the predictive hazard assessment of realistic pesticide mixtures. Aquatic Toxicology, 76 (2), 93-110. doi:10.1016/j.aquatox.2005.10.001

Kern, S., Fenner, K., Singer, H. P., Schwarzenbach, R. P., \& Hollender, J., 2009. Identification of transformation products of organic contaminants in natural waters by computer-aided prediction and high-resolution mass spectrometry. Environmental Science and Technology, 43 (18), 7039-7046.

Kortenkamp, A., Backhaus, T., \& Faust, M., 2009. State of the Art Report on Mixture Toxicity. Final Report. Report to the EU Commission, Directorate General for the Environment, 2009. http://ec.europa.eu/environment/chemicals/effects/pdf/report mixture toxicity.pdf (15.05.2016)

Kuzmanović, M., López-Doval, J. C., De Castro-Catalá, N., Guasch, H., Petrović, M., Muñoz, I., Ginebreda, A., \& Barceló, D., 2015. Ecotoxicological risk assessment of chemical pollution in four Iberian river basins and its relationship with the aquatic macroinvertebrate community status. Science of the Total Environment. doi:10.1016/j.scitotenv.2015.06.112

Li, Z., Sobek, A., \& Radke, M., 2016. Fate of Pharmaceuticals and their Transformation Products in four small European Rivers receiving treated Wastewater. Environmental Science and Technology. doi:10.1021/acs.est.5b06327

Liess, M., \& Von Der Ohe, P. C., 2005. Analyzing effects of pesticides on invertebrate communities in streams. Environmental Toxicology and Chemistry, 24 (4), 954-965. doi:10.1897/03-652.1 
Loewe, S., \& Muischnek, H., 1926. About combined effects I. Note: Über Kombinationswirkungen I. Mitteilung: Tool for problem formulation (in German). Naunyn-Schmiedebergs Arch. Exp. Pathol. Pharmakol., 114, 313-326.

Loos, R., Carvalho, R., António, D. C., Comero, S., Locoro, G., Tavazzi, S., Paracchini, B., Ghiani, M., Lettieri, T., Blaha, L., Jarosova, B., Voorspoels, S., Servaes, K., Haglund, P., Fick, J., Lindberg, R. H., Schwesig, D., \& Gawlik, B. M., 2013. EU-wide monitoring survey on emerging polar organic contaminants in wastewater treatment plant effluents. Water Research, 47 (17), 6475-6487. doi:10.1016/j.watres.2013.08.024

Malaj, E., von der Ohe, P. C., Grote, M., Kühne, R., Mondy, C. P., Usseglio-Polatera, P., Brack, W., \& Schäfer, R. B., 2014. Organic chemicals jeopardize the health of freshwater ecosystems on the continental scale. PNAS, Proceedings of the National Academy of Sciences, 111 (26), 9549-9554. doi:10.1073/pnas.1321082111

Matamoros, V., Rodríguez, Y., \& Albaigés, J., 2016. A comparative assessment of intensive and extensive wastewater treatment technologies for removing emerging contaminants in small communities. Water Research, 88, 777-785. doi:10.1016/j.watres.2015.10.058

Moschet, C., Wittmer, I., Simovic, J., Junghans, M., Piazzoli, A., Singer, H., Stamm, C., Leu, C., \& Hollender, J., 2014. How a complete pesticide screening changes the assessment of surface water quality. Environmental Science and Technology, 48 (10), 5423-5432. doi:10.1021/es500371t

Müller, K., Bach, M., Hartmann, H., Spiteller, M., \& Frede, H. G., 2002. Point- and nonpoint-source pesticide contamination in the Zwester Ohm catchment, Germany. Journal of Environmental Quality, 31 (1), 309-318.

Neumann, M., Schulz, R., Schäfer, K., Müller, W., Mannheller, W., \& Liess, M., 2002. The significance of entry routes as point and non-point sources of pesticides in small streams. Water Research, 36 (4), 835-842. doi:10.1016/S0043-1354(01)00310-4

OPB, 2005. Ordinance on Biocidal Products. https://www.admin.ch/opc/en/classifiedcompilation/20021524/index.html (17.10.2016)

OPPP, 2010. Ordinance on Plant Protection Products (in German). https://www.admin.ch/opc/de/classified-compilation/20100203/index.html (17.10.2016)

Petrie, B., Barden, R., \& Kasprzyk-Hordern, B., 2015. A review on emerging contaminants in wastewaters and the environment: current knowledge, understudied areas and 
recommendations for future monitoring. Water Research, 72, 3-27. doi:10.1016/j.watres.2014.08.053

Posthuma, L., \& De Zwart, D., 2006. Predicted effects of toxicant mixtures are confirmed by changes in fish species assemblages in Ohio, USA, Rivers. Environmental Toxicology and Chemistry, 25 (4), 1094-1105. doi:10.1897/05-305r.1

Posthuma, L., \& de Zwart, D., 2012. Predicted mixture toxic pressure relates to observed fraction of benthic macrofauna species impacted by contaminant mixtures. Environmental Toxicology and Chemistry, 31 (9), 2175-2188. doi:10.1002/etc.1923

Posthuma, L., Suter, G. W., \& Traas, T. P., 2002. Species sensitivity distributions in ecotoxicology. Boca Raton: Lewis.

R Development Core Team, 2008. R: A language and environment for statistical computing: R Foundation for Statistical Computing: Vienna, Austria. http://www.R-project.org

Schäfer, R. B., von der Ohe, P. C., Kühne, R., Schüürmann, G., \& Liess, M., 2011. Occurrence and Toxicity of 331 Organic Pollutants in Large Rivers of North Germany over a Decade (1994 to 2004). Environmental Science and Technology, 45 (14), 6167-6174. doi:10.1021/es2013006

Schwarzenbach, R. P., Escher, B. I., Fenner, K., Hofstetter, T. B., Johnson, C. A., von Gunten, U., \& Wehrli, B., 2006. The challenge of micropollutants in aquatic systems. Science, 313 (5790), 1072-1077. doi:10.1126/science.1127291

Schymanski E. L., Singer, H. P., Longrée, P., Loos, M., Ruff, M., Stravs, M. A., Ripollés Vidal, C., Hollender J., 2014. Strategies to Characterize Polar Organic Contaminants in Wastewater: Exploring the Capability of High Resolution Mass Spectrometry. Environmental Science and Technology, 48, 1811-1818. doi: 10.1021/es4044374

Smetanová, S., Bláha, L., Liess, M., Schäfer, R. B., \& Beketov, M. A., 2014. Do predictions from Species Sensitivity Distributions match with field data? Environmental Pollution, 189, 126-133. doi:10.1016/j.envpol.2014.03.002

SPEAR Calculator, 2016 (Version 0.9.0). http://www.systemecology.eu/spearcalc/index.de.html. (17.02.2016)

Stalter, D., Magdeburg, A., Quednow, K., Botzat, A., \& Oehlmann, J., 2013. Do contaminants originating from state-of-the-art treated wastewater impact the ecological quality of surface waters? PLoS One, 8 (4), e60616. doi:10.1371/journal.pone.0060616 
Stamm, C., Räsänen, K., Burdon, F. J., Altermatt, F., Jokela, J., Joss, A., Ackermann, M., \& Eggen, R. I. L., 2016. Unravelling the impacts of micropollutants in aquatic ecosystems: Interdisciplinary studies at the interface of large-scale ecology. Advances in Ecological Research, 55, 183-223.

Stucki, P., 2010. Methods for the investigation and analysis of streams: macroinvertebrates level F (in German). Umwelt-Vollzug 1026. BAFU, Bern. 61 pp.

Sun, Q., Lv, M., Hu, A. Y., Yang, X. Y., \& Yu, C. P., 2014. Seasonal variation in the occurrence and removal of pharmaceuticals and personal care products in a wastewater treatment plant in Xiamen, China. Journal of Hazardous Materials, 277, 69-75. doi:10.1016/j.jhazmat.2013.11.056

Triebskorn, R., Blaha, L., Engesser, B., Güde, H., Hetzenauer, H., Henneberg, A., Köhler, H.-R., Krais, S., Maier, D., Peschke, K., Thellmann, P., Vogel, H.-J., Kuch, B., Oehlmann, J., Rault, M., Suchail, S., Rey, P., Richter, D., Sacher, F., Weyhmüller, M., \& Wurm, K., 2013. SchussenAktiv - a model study for efficiency of reduction of anthropogenic trace substances by active carbon in wastewater treatment plant: exposure and effect monitoring before start up of the adsorption step of the wastewater treatment plant Langwiese (AZV Mariatal). (in German) Korrespondenz Wasserwirtschaft, 8, 427-436. doi:10.3243/kwe2013.08.001

Vieno, N. M., Tuhkanen, T., \& Kronberg, L., 2005. Seasonal variation in the occurrence of pharmaceuticals in effluents from a sewage treatment plant and in the recipient water. Environmental Science and Technology, 39 (21), 8220-8226. doi:10.1021/es051124k

Wittmer, I. K., Bader, H. P., Scheidegger, R., Singer, H., Lück, A., Hanke, I., Carlsson, C., \& Stamm, C., 2010. Significance of urban and agricultural land use for biocide and pesticide dynamics in surface waters. Water Research, 44 (9), 2850-2862. doi:10.1016/j.watres.2010.01.030 